\title{
MEMÓRIA RETÓRICO-ARGUMENTATIVA: ENCONTRO ENTRE PERELMAN E PÊCHEUX
}

\section{RHETORICAL-ARGUMENTATIVE MEMORY: ENCOUNTER BETWEEN PERELMAN AND PÊCHEUX}

\author{
Maria Alejandra Vitale* \\ Universidad de Buenos Aires, Buenos Aires, Argentina
}

\begin{abstract}
Resumo: 0 objetivo deste trabalho é discutir a noção de memória retórico-argumentativa e ilustrá-la com editoriais e artigos da imprensa escrita brasileira que apoiou o golpe de Estado ocorrido em 31 de março de 1964, nos quais foram reinscritos discursos produzidos pela mídia escrita da Argentina que argumentaram a favor das sucessivas quedas da democracia sofridas por esse país durante 0 século XX². Para isso, irei me concentrar, primeiramente, na dimensão argumentativa das memórias discursivas e, como aporte para estudá-la, considerarei as técnicas argumentativas caracterizadas por Chaïm Perelman, apesar das diferenças epistemológicas que 0 separam da análise do discurso francesa, especificamente das propostas de Michel Pêcheux.
\end{abstract}

Palavras-chave: Memória retórico-argumentativa; Perelman; Pêcheux; Ditadura Militar; Imprensa.

\begin{abstract}
This paper aims to discuss the notion of rhetorical-argumentative memory and illustrate it through the analysis of Brazilian written press editorials and articles which supported the coup d'etat that took place in March 37st, 1964. In these texts, discourses produced by Argentinian written press arguing in favor of the successive falls of democracy in the country during the 20th century were reinscribed. In order to achieve the objectives, I will, first, concentrate on the argumentative dimension of the discursive memories and, as a framework to study them, I will consider the argumentative techniques characterized by Chaïm Perelman, in spite of the epistemological differences that distinguish him from French Discourse Analysis, specifically from Michel Pêcheux's proposals.
\end{abstract}

Keywords: Rhetorical-Argumentative Memory; Perelman; Pêcheux; Military Dictatorship; Press.

\footnotetext{
* Doutora da Universidad de Buenos Aires - UBA, Buenos Aires, Argentina; vitaleale@hotmail.com

1 Tradução do original espanhol por Juan Facundo Sarmiento (UESC) e Eduardo Lopes Piris (UESC).

2 Na Argentina houve seis golpes de Estado: em 1930 foi derrubado o radical Hipólito Yrigoyen; em 1943, o golpe foi contra o conservador Ramón Castillo; em 1955, contra o justicialista Juan Domingo Perón. Em 1962, foi derrubado Arturo Frondizi; em 1966, o radical Arturo Illia e em 1976, Isabel Perón.
} 
Linha D'Água (Online), São Paulo, v. 29, n. 2, p. 156-172, dez. 2016

\section{Memória discursiva, argumentação e retórica}

Sabe-se que a última etapa das investigações de Pêcheux, inseridas no projeto ADELA (Analyse de Discours et Lecture d'Archive), simboliza o crescente interesse na problemática da memória discursiva. Pêcheux reflete então acerca do que ele chama de espaço de memória de uma sequência discursiva, noção que se assimila à de interdiscurso e que dá conta do corpo sócio-histórico de traços discursivos prévios nos quais essa sequência se inscreve. Sua última intervenção acadêmica (PECCHEUX, 1990), uma conferência feita em 1981 na Universidade de Illinois Urbana-Champaign, Estados Unidos da América, reivindica a Análise do Discurso como uma prática de interpretação de uma sequência discursiva que necessariamente coloca em jogo um discurso-outro como espaço virtual leitura, discurso-outro que marca, no interior dessa sequência, suas redes de filiações históricas.

Pêcheux escreveu a apresentação do texto, hoje clássico, de Jean-Jacques Courtine (1981) sobre o discurso comunista endereçado aos cristãos. Com base na releitura de $A$ arqueologia do saber, de Michel Foucault, e particularmente nas noções de domínio de memória e de arquivo ${ }^{3}$, Courtine propôs estudar as formações discursivas enquanto memórias discursivas, concebidas como retorno, transformação ou esquecimento, na atualização de um acontecimento discursivo, de enunciados já ditos anteriormente.

O interesse de Pêcheux pelo tema da memória discursiva esteve marcado pela focalização da heterogeneidade enunciativa, resultado de seu encontro intelectual ${ }^{4}$ com Jacqueline Authier-Revuz $(1995,1998)^{5}$, que, por meio da noção de hetero-

3 Em Foucault (1987, p. 95), o termo domínio de memória refere-se a "enunciados [...] em relação aos quais se estabelecem laços de filiação, gênese, transformação, continuidade e descontinuidade históricas". No que concerne ao arquivo, Foucault o entende como a lei que rege o que pode ser dito, o sistema que regula o surgimento dos enunciados como acontecimentos singulares e o sistema geral da formação e transformação dos enunciados.

4 Maldidier (1990) lembra que Pêcheux conheceu Authier-Revuz no Centre d'Etudes et de Recheches Marxistes (CERM) em meados dos anos setenta e se encontrou novamente com ela no Colóquio "Matérialités Discursives", em 1980, o que marcou o início de uma colaboração que continuaria até a sua morte.

5 Os primeiros caminhos da Análise do Discurso, especificamente o livro de Pêcheux Analyse automatique du discours, de 1969, orientaram para a redução do múltiplo e heterogêneo, para 
Linha D'Água (Online), São Paulo, v. 29, n. 2, p. 156-172, dez. 2016

geneidade constitutiva, apontou para o fato de que em todo discurso existe sempre um Outro - presença permanente indicada/reconhecida implicitamente -, que o determina desde fora do sujeito, o qual é mais falado do que falante. Este "fora", no entanto, é um exterior dentro do sujeito, no sentido em que é condição constitutiva da sua existência e de seu próprio discurso ${ }^{6}$.

Com filiação nesta tradição teórica, na América Latina, particularmente no Brasil e na Argentina, a memória discursiva foi estudada como sentidos historicamente sedimentados na reconfiguração constante de processos de reformulação parafrástica e em relação com as matrizes discursivas e os discursos fundadores. As memórias discursivas têm sido abordadas como construtoras de identidades nacionais ou políticas e como regimes de enunciabilidade, matrizes de inclusão e de exclusão de enunciados que determinam o que pode ou não pode ser dito a partir de diferentes posições ideológicas (ARNOUX, 2008; INDURSKY, 2003, 2011; ORLANDI, 1993; ZOPPI-FONTANA, 2004). No entanto, tem sido pouco focalizada a dimensão argumentativa das memórias discursivas, o que se confirma no verbete do Diccionario de análisis del discurso (CHARAUDEAU; MAINGUENEAU, 2005), em que - ao resenhar novos enfoques de estudos sobre as memórias discursivas, como o proposto por Charaudeau (2004), que as aborda em relação aos gêneros discursivos $^{7}$ - não se leva em consideração o caso em que o retorno do já dito tem a função de provocar a adesão em favor de uma tese apresentada ao assentimento.

o mesmo e homogêneo. De fato, o método proposto por Pêcheux buscava a invariante proposicional em uma família parafrástica em corpora selecionados conforme condições de produção estáveis e homogêneas, o que aumentou a distância para a consideração da heterogeneidade.

6 A heterogeneidade constitutiva põe em jogo o inconsciente e o interdiscurso. A heterogeneidade mostrada, no entanto, é uma inscrição do outro no fio do discurso, que altera sua unicidade aparente. Mediante essa heterogeneidade, descrita pela Linguística, o sujeito falante indica que uma parte do seu discurso não lhe pertence. Como é sabido, a hipótese de Authier-Revuz é que a heterogeneidade mostrada é um modo de negociação - obrigado - com a heterogeneidade constitutiva, que é necessário desconhecer para poder enunciar um discurso.

7 Charaudeau (2004) recolocou a reflexão acerca da memória discursiva vinculando-a à problemática dos gêneros discursivos. Desse modo, postula que três tipos de memória são inerentes aos gêneros: uma memória dos discursos, que se constitui em torno dos saberes de conhecimento e de crença sobre o mundo; uma memória das situações de comunicação, que se constitui em torno dos contratos de comunicação; e uma memória das formas, que se constitui em torno das maneiras de dizer. 
Para estudar a dimensão argumentativa das memórias discursivas, cunhei o termo "memória retórico-argumentativa", com referência às estratégias persuasivas que, em uma série discursiva, visam a conquistar a adesão acerca de uma determinada tese. Tenho utilizado esta noção para estudar os editoriais e os artigos de opinião que a imprensa da Argentina produziu para apoiar os sucessivos golpes militares que o País sofreu durante o período 1930-1976 (VITALE, 2006).

A dimensão argumentativa das memórias discursivas assume inquestionável relevância para o estudo de gêneros (ADAM; HEIDMANN, 2004; BAJTÍN, 1982) inscritos em instituições que constroem consenso na opinião pública, como os meios de comunicação, e que são notoriamente argumentativos, como os editoriais e os artigos de opinião (HERMAN; JUFER, 2001).

O termo "memória retórico-argumentativa" remete a uma perspectiva retórica de estudo da argumentação, em que as técnicas argumentativas descritas por Chaïm Perelman ocupam um lugar central. Porém, é pertinente lembrar que a teoria do discurso de Pêcheux não apenas priorizou a análise de nível sintático e lexical, sem focalizar o plano argumentativo dos enunciados, como também rechaçou explicitamente o idealismo que percebeu na linguística do discurso ou da enunciação, da qual Perelman, tal como interpreta corretamente Amossy (2002), foi precursor.

De fato, no Tratado da Argumentação, especialmente nos capítulos dedicados à "escolha dos dados e sua adaptação com vistas à argumentação" e à "apresentação dos dados e forma do discurso", destacam-se os comentários sobre o valor argumentativo dos epítetos, as qualificações, as escolhas lexicais, as modalidades e os pronomes, entre outros elementos da linguagem que manifestam a presença da subjetividade. Como assinala Amossy (2002), Perelman dedica a mesma atenção que a linguística do discurso - na sua vertente enunciativa e pragmática - dedica aos quadros da enunciação, à função do alocutário, ao saber comum e aos pressupostos que autorizam a interação verbal, à eficácia da fala definida em termos de ação.

Por sua vez, Pêcheux (1978) entende que as teorias da enunciação reproduzem, no nível teórico, a "ilusão do sujeito, através da ideia de um sujeito enunciador portador de escolha, intenções, decisões etc. na tradição da Bally, Jakobson, Benveniste [...]" (1978 [1975], p. 249). A zona de constituição da subjetividade é, no entanto, inacessível ao sujeito e está ligada ao inconsciente e à ideologia, a 
Linha D'Água (Online), São Paulo, v. 29, n. 2, p. 156-172, dez. 2016

qual - como observou Louis Althusser (1988) - constitui os indivíduos em sujeito por meio da interpelação. A Nova Retórica de Perelman não compartilha os fundamentos epistemológicos da psicanálise e do materialismo histórico, que são fundamentais para a teoria do discurso de Pêcheux ${ }^{8}$, porém se constitui no âmbito do liberalismo político que valoriza o pluralismo como um marco indispensável para uma convivência pacífica entre aqueles que pensam de forma diferente. Dessa maneira, à noção de luta de classes, central na proposta de Pêcheux, opõe-se a ideia perelmaninana do razoável (ANGENOT, 2012), que tem como horizonte o consenso9. Amossy (2012) admite que Perelman considera os fatores sociais e culturais que caracterizam os participantes de um debate e que, mesmo em sua teoria do auditório universal, destaca que o que resulta razoável depende do que aparece como tal em um período e em um lugar determinados ${ }^{10}$. Porém, enfatiza que a visão de Perelman acerca da relatividade e da pluralidade do razoável não se estende a uma perspectiva da sociedade em que as relações de poder, a divergência de interesses e as diferenças ideológicas profundas convertem o conflito e o agon ${ }^{11}$ no motor da democracia.

A partir da compreensão dessas diferenças marcadas, é possível, no entanto, postular que as memórias retórico-argumentativas, inerentes a posições ideológicas,

8 Na última etapa de sua obra, Pêcheux (1990) distanciou-se do marxismo, entendido como ciência régia, para a análise do discurso, assumiu que o ponto fraco da teoria de Althusser sobre os Aparelhos Ideológicos de Estado era sua concepção reprodutivista e coincidiu com a crítica da tese de ideologia dominante, associando-a a uma velha certeza elitista de que as classes dominadas não são incapazes de inventar nada porque estão absorvidas pela lógica da vida cotidiana.

9 Danblon (2005, p. 80), por sua vez, sutenta que: "o razoável na obra de Perelman pode ser definido como o que reúne o mais amplo consenso possível em torno daqueles que se consideram como 'interlocutores' dentro de uma comunidade".

10 Perelman retoma a noção de auditório universal entendido como qualquer homem iluminado pelas luzes da razão que será convencido por razões de força maior. No entanto, salienta que cada cultura e cada indivíduo têm uma representação do auditório universal, a noção que é muitas vezes acompanhada por um sistema de exclusão daqueles que estão fora da razão, a humanidade ou aquilo considerado "normal". Para uma reflexão sobre o auditório universal em Perelman, consulte Danblon (2004).

1 NT: Conforme Novíssimo Aulete - dicionário contemporâneo da língua portuguesa: "Na antiga comédia grega, parte em que duas personagens desenvolvem um debate que vai definir o conflito básico da peça". 
Linha D'Água (Online), São Paulo, v. 29, n. 2, p. 156-172, dez. 2016

incluem o retorno, a reformulação ou o esquecimento de estratégias persuasivas que podem ser analisadas por meio dos tipos de argumentos descritos por Perelman ${ }^{12}$.

\section{Memória retórico-argumentativa e golpismo no Brasil e na Argentina}

A seguir, ilustrarei o que foi dito, analisando discursos golpistas produzidos no Brasil em 1964, os quais retomaram técnicas argumentativas observadas em discursos golpistas, anteriormente, produzidos na Argentina e que, posteriormente, retornariam a este país para construir consenso a favor dos golpes de Estado de 28 de junho 1966 e de 24 de março de 1976.

\section{a) A dissociação da noção de democracia}

Segundo Perelman e Olbrechts-Tyteca (1989 [1958]), a dissociação das noções pressupõe a unidade primitiva de elementos confundidos no interior de uma mesma concepção, designados por uma única noção, no caso analisado, a noção de democracia. Para argumentar a favor da queda de João Goulart, a noção de democracia foi dissociada em uma democracia falsa, não autêntica e formal e uma democracia verdadeira, autêntica e com conteúdo, o que foi garantido pelo golpe de Estado. O Jornal de Brasil, por exemplo, afirmou que os militares: "Arriscaram a carreira e as vidas por um Brasil melhor, por uma democracia mais autêntica"13. Nesses discursos, a falsidade, não autenticidade e formalidade da democracia vigente durante o governo do presidente Goulart, foi vinculada, pela imprensa, à comunização do Brasil, à corrupção e à violação da legalidade, as quais foram atribuídas ao governo destituído. Por isso, por exemplo, O Estado de Minas referia-se a:

guerrido povo mineiro que se dispôs a lutar pela volta de um regime democrático autêntico, sem conivência com o comunismo e também sem corrupções ${ }^{14}$.

\footnotetext{
12 As memórias retórico-argumentativas são formadas, também, pelo retorno e transformação de alguns modos de dizer relacionadas com o ethos. A esse respeito, ver Vitale (2006).

13 Jornal do Brasil, "Autoridade e confiança", edição de 5 de abril de 1964.

14 O Estado de Minas, editorial de 7 de abril de 1964.
} 
Linha D'Água (Online), São Paulo, v. 29, n. 2, p. 156-172, dez. 2016

$\mathrm{Na}$ citação, se observa, também, que $\mathrm{O}$ Estado de Minas representou o povo como o agente que lutou pela democracia, o que visava legitimar as Forças Armadas Brasileiras como representantes do povo.

Nestas argumentações que desenvolveu a mídia impressa do Brasil para apoiar a queda de João Goulart, operou a memória retórico-argumentativa, uma vez que os enunciados citados integraram a seguinte rede de reformulações parafrásticas interdiscursivas (FUCHS, 1994), formada por sequências discursivas que dissociam a noção de democracia e que remontem aos discursos fundadores ${ }^{15}$ do golpismo de 1930 na Argentina:

1930: "A Junta Militar assumiu o poder para que volte a ser uma verdadeira democracia" (Atlántida, "Vida que passa", 18 de setembro de 1930).

1955: "[...] o caminho da verdadeira democracia" (Esto es, "Uma geração que reencontra", 10 de outubro de 1955).

1964: "Arriscaram a carreira e as vidas por um Brasil melhor, por uma democracia mais autêntica"16 / "O aguerrido povo mineiro que se dispôs a lutar pela volta de um regime democrático autentico, sem conivência com o comunismo e também sem corrupções" (O Estado de Minas, editorial de 7 de abril de 1964). 1966: "[...] a restauração de uma autêntica democracia" (Confirmado, "Moral e mudança de estruturas", 4 de agosto de 1966).

1976: "As condições para que a democracia autêntica possa funcionar" (La Prensa, editorial de 25 de março de 1976).

Nesta rede, observa-se como a noção de democracia foi dissociada em diversas conjunturas golpistas da Argentina para vincular, de modo implícito, os governos destituídos às democracias não autênticas e falsas e, assim, legitimar os golpes de Estado, situados de maneira implícita - ou explícita - com uma posição democrática.

15 Orlandi (1993) caracteriza os discursos fundadores como aqueles que criam uma nova tradição de sentidos e instituem uma memória discursiva, pois geram a possibilidade e as regras de formação de outros discursos.

16 Jornal do Brasil, "Autoridade e confiança", 5 de abril de 1964. 
Linha D'Água (Online), São Paulo, v. 29, n. 2, p. 156-172, dez. 2016

A construção das forças armadas como democráticas, por outro lado, se inscreveu na materialidade linguística em enunciados negativos que refutaram afirmações críticas implícitas, segundo as quais os governos militares eram uma ditadura. Trata-se de negações que Oswald Ducrot denomina metalinguísticas, que opõem dois locutores diferentes ou um único locutor em momentos diferentes, e que sempre são desqualificadoras de um contexto do discurso prévio (GARCIA NEGRONI, 1998). Dessa maneira, O Estado de Minas, por exemplo, sustentou: "As Forças Armadas Brasileiras não pleiteiam a ditadura" ${ }^{17}$. Na Argentina, a revista Análisis afirmou, em 1966, com referência ao golpe de Estado, que "não houve intenção de instalar uma ditadura”" ${ }^{18}$ e, em 1976, o jornal La Razón formulou "não se forjou uma ditadura" ${ }^{19}$.

No caso do Brasil, a imprensa refutou também as críticas que a mídia da França dirigiu ao golpe militar, pelo fato de o mesmo ter sido apoiado pelos Estados Unidos. O Globo denunciou que tais críticas foram motivadas pela rivalidade entre franceses e norte-americanos devido à disputa pela liderança do mundo não-comunista e revidou o ataque, considerando que era o governo de Goulart que estava sendo comandado por um país estrangeiro (aludindo à China) ${ }^{20}$. A imprensa brasileira também colocou em dúvida a independência da política exterior do governo de Goulart, que priorizou a relação com os países não-alinhados e o conflito Norte-Sul, dando a entender que essa política respondia à área dos países comunistas ${ }^{21}$.

\section{b) A retórica como expediente}

A identificação dos governos destituídos com o não autêntico e falso convergiu com o argumento que Perelman e Olbrechts-Tyteca denominam a retórica como expediente, que desqualifica a retórica identificando-a com o artificial, falso e verbal

\footnotetext{
17 O Estado do Minas, "O Episódio da liberação do Brasil", 5 de abril de 1964.

18 Análisis, "Modernidade: a questão é como?", 18 de julho de 1966.

19 La Razón, "Estes são os segredos que o Presidente manejará sem demagogias nem altissonâncias, diante de um novo estilo", 27 de março de 1976.

20 O Globo, "Schmidt: Esta foi uma revolução brasileira", 6 de abril de 1964.

21 O Globo, "Sabotagem e Audácia", 10 de abril de 1964.
} 
Linha D'Água (Online), São Paulo, v. 29, n. 2, p. 156-172, dez. 2016

frente ao natural, verdadeiro e real. Assim, $\mathrm{O}$ Globo qualificou como retóricas as palavras usadas por Goulart - avaliado pelo jornal como um orador medíocre e sem eloquência ${ }^{22}$ - e, por outro lado, valorizou a palavra do Marechal Humberto Castelo Branco como "digna, serena, correta" 23 .

$\mathrm{O}$ argumento da retórica como expediente e o enlace metonímico entre o elogio do discurso do orador e o próprio orador se integrou na memória retórico -argumentativa, a qual se manifestou na seguinte rede de reformulações parafrásticas interdiscursivas que remonta à Argentina de 1930:

1930: "[...] a oratória enganosa, destinada para lisonjear os baixos instintos populares com vistas ao êxito eleitoral" ("Palavras novas, novo estilo", La Fronda, 9 de setembro de 1930).

1955: "[...] a concisão e a clareza da sua linguagem [do novo chefe do Exército], desprovida de inúteis ostentações oratórias" ("Hora de colaboração", Clarín, 25 de setembro de 1955).

1964: "[...] uma palavra digna, serena, correta" ( O Globo, "Castelo Branco", 7 de abril de 1964).

1966. “[...] seus [do ex-presidente Arturo Illia] próprios requerimentos de diálogo se mostraram como algo meramente retórico" (La Nación, editorial de 29 de julho de 1966).

1976. "[...] as aproximações e as figuras de linguagem que não resistem uma análise mais aprofundada" (Clarín, 17 de março de 1976).

$\mathrm{Na}$ série ilustrada, o argumento da retórica como expediente orientou a favor dos golpes militares representando - implicitamente em 1955 - o discurso dos governos civis destituídos como sendo enganoso e desvinculado da realidade. No caso do Brasil, a palavra política de João Goulart foi implicitamente construída como indigna, contorcida e incorreta. As Forças Armadas, no entanto, foram construídas - de modo explícito em 1955 e em 1964 e de modo implícito nos

O Globo, "O show da cidade", 4 de abril de 1964.

O Globo, "Castelo Branco", 7 de abril de 1964. 
Linha D'Água (Online), São Paulo, v. 29, n. 2, p. 156-172, dez. 2016

golpes restantes - como um discurso sem retórica, e por isso vinculadas ao natural, verdadeiro e real.

\section{c) $\mathbf{O}$ argumento da direção}

Segundo o Tratado da Argumentação (Perelman; Olbrechts-Tyteca, 1989 [1958]), o argumento da direção (incluído entre os argumentos baseados na estrutura do real, especificamente nas ligações de sucessão) implica a existência de uma série de etapas em direção a um objeto determinado - temido, na maioria das vezes - e a dificuldade, ou a impossibilidade, de parar no meio do caminho. Por meio deste argumento, os jornais representaram o Brasil em uma queda sem freio rumo ao abismo, a anarquia, a dissolução e o comunismo, e fizeram entender que os militares pararam essa decorrada quando eles destituíram o presidente João Goulart. O Globo, por exemplo, afirmou:

Só agora, depois de expulso, o Presidente da República, que se achava entrosado, se não integrado, em um "complot" comunista, é que a Nação se apercebe até que ponto estêve próxima de rolar pelo abismo que lhe haviam preparado ${ }^{24}$.

O argumento da direção se articulou com a metáfora orientacional (LAKOFF; JOHNSON, 1995), que pode ser resumida como "o bem está acima/o mal está abaixo" e, por meio da memória retórico-argumentativa, se integrou na seguinte rede de reformulações parafrásticas interdiscursivas ${ }^{25}$ :

1930. "[...] o abismo moral e econômico para o qual estava sendo empurrado o país" (Atlántida, "Vida que passa", 18 de setembro de 1930).

1943. “[...] o abismo da falência moral, política e econômica” (Cabildo, editorial de 5 de junho de 1943).

24 O Globo, "O expurgo", 6 de abril de 1964.

25 Para um estudo do sentido que adquiriu o abismo em cada conjuntura do golpe, consulte Vitale (2007). 
Linha D'Água (Online), São Paulo, v. 29, n. 2, p. 156-172, dez. 2016

1955. "[...] o abismo em que se afundava a República" (Clarín, "Encontro de honra com a liberdade", 23 de setembro de 1955).

1962. "[...] as atitudes [de Arturo Frondizi] que pareciam levá-lo a um rumo perigoso" (Proclamação militar) ${ }^{26}$.

1964. “[...] a Nação se apercebe até que ponto estêve próxima de rolar pelo abismo que lhe haviam preparado" (O Globo, "O expurgo", 6 de abril de 1964)

1966. "[...] um governo incompreensivelmente determinado a avançar rumo ao abismo" (Clarin, editorial de 3 de julho de 1966).

1976. "o abismo da desintegração econômica e da anarquia política" (La Prensa, editorial 28 de março de 1976) / "A Argentina se desliza direto para abismos ainda mais profundos. Por isso, é hora de deter a queda." (Clarín, 17 de março de 1976.)

Na dimensão do pathos (PLANTIN, 2011), o argumento da direção estava orientado a despertar no auditório emoções como o medo ou a angústia perante os governos destituídos e alívio e tranquilidade perante os golpes de Estado, os quais, segundos os discursos jornalísticos, pararam a tão temida queda em que supostamente se encontravam Brasil e Argentina.

\section{d) A metáfora biológico-médica da doença}

Sabe-se que Perelman e Olbrechts-Tyteca (1989 [1958], p. 611) concebem a metáfora, tipo de ligação que fundamenta a estrutura do real, como uma analogia condensada, que resulta da fusão de um elemento do foro (o conjunto dos termos $\mathrm{C}$ e $\mathrm{D}$, os quais servem para sustentar o raciocínio) com um elemento do tema (o conjunto dos termos A e B, os quais contêm a conclusão). A metáfora biológicomédica da doença manifesta a particularidade de que os elementos do foro pertencem ao campo do organismo humano e os do tema ao campo político e social, que, ao ser assimilados pelos primeiros, são biologizados. Por isso, esta metáfora realiza

26 O presidente Arturo Frondizi foi destituído em 29 de março de 1962. 
Linha D'Água (Online), São Paulo, v. 29, n. 2, p. 156-172, dez. 2016

completamente uma das operações fundamentais da ideologia: a naturalização de processos que são de índole sócio-histórica (EAGLETON, 1997, p. 88).

Por meio desta metáfora, a imprensa brasileira representou, implicitamente, as Forças Armadas como médicos que vieram para curar um organismo doente e também como cirurgiões que realizaram uma extirpação ou uma operação cirúrgica para curar o corpo social. Dessa maneira, $\mathrm{O}$ Globo publicou dois artigos assinados que metaforizaram o comunismo como um "câncer" e um "abscesso"27, sendo que, e um deles afirmou: "A infecção do organismo tinha vínculos profundos e precisam ser removidos"28.

O Jornal do Brasil, por sua vez, metaforizou, como uma "cirurgia", o Ato Institucional número 1 (instrumento jurídico sancionado pelas Forças Armadas para institucionalizar o governo militar), que estabeleceu, na prática, poderes extra-constitucionais (ALVES, 1989) e foi o equivalente brasileiro do Estatuto da Revolução Argentina, que se sobrepôs à Constituição da Argentina, em 1966, por ação dos militares:

Disposições institucionais que permitam ao Govêrno triunfante praticar a cirurgia que os órgãos do ordenamento normal das instituições se recusariam a fazer ${ }^{29}$

Nestes enunciados, desenvolve-se também a memória retórico-argumentativa, que se manifestou na seguinte rede de reformulações parafrásticas interdiscursivas:

1930. "A intervenção cirúrgica" (La Nueva República, 5 de setembro de 1930).

1943. "A espada, atuando como bisturi, abriu o abscesso; somente resta que se chegue a penetrar até o foco e que um cauterizador, que alguns tacharão de cruel, mas indispensável, esvazie a bolsa de infecção e devolva a saúde ao corpo inteiro" “Considerações sobre a revolução”, Criterio, 17 de junho de 1943).

27 O Globo referiu-se ao "câncer comunista", em "Operação limpeza", de 10 de abril de 1964, e ao "abscesso comunista", em "A traição e as sanções", de 10 de abril de 1964.

28 O Globo, "Operação Limpeza", 10 de abril de 1964.

29 Jornal do Brasil, "Limites do expurgo e retorno ao regime", 7 de abril de 1964. 
Linha D'Água (Online), São Paulo, v. 29, n. 2, p. 156-172, dez. 2016

1964. "[...] disposições institucionais, que permitam ao Govêrno triunfante praticar a cirurgia que órgãos do ordenamento normal das instituições se recusariam a fazer" (Jornal do Brasil, "Limites do expurgo e retorno ao regime", 7 de abril de 1964).

1966. "É salutar que se digam estas verdades, ainda que nos doam. Há muita semelhança com o que os médicos reconhecem como 'injúrias cirúrgicas', inseparáveis e necessárias em toda operação". (Clarin, editorial de 5 de julho de 1966).

1976. "Não se esquecer de que os militares tiveram que fazer uma das operações cirúrgicas mais difíceis e minuciosas da história argentina: o governo derrubado havia recebido 7.500 .000 votos" (Extra, "O desencanto como mania", maio de 1976).

Esta metáfora tendeu a ativar, no auditório, noções de uma doxa compartilhada, o valor negativo da doença e o positivo da saúde, para definir e interpretar a realidade social de uma forma que fosse favorável aos interesses das Forças Armadas e dos setores sociais que as apoiaram. Como afirmam Lakoff e Johnson (1995), as metáforas modelam a nossa percepção dos acontecimentos, a nossa experiência e as nossas ações, daí que o uso da metáfora biológico-médica da doença por parte da imprensa brasileira e argentina - e particularmente a metaforização dos militares como cirurgiões que realizavam extirpações ou operações cirúrgicas que penetravam e cerceavam os corpos - favoreceu a legitimação pública das práticas repressivas que, de modo secreto e oculto, eram executadas pelos militares.

O interesse da metáfora biológico-médica da doença encontra-se, portanto, em que mostra ao mesmo tempo que oculta uma biopolítica, os modos pelos quais o poder penetra no próprio corpo dos sujeitos e nas suas formas de vida; nas palavras de Agamben (1998, p. 151), “a crescente implicação da vida natural do homem nos mecanismos e nas práticas do poder". 
Linha D'Água (Online), São Paulo, v. 29, n. 2, p. 156-172, dez. 2016

\section{Conclusão}

Considero que a noção de memória retórico-argumentativa permite abordar a natureza heterogênea de toda palavra argumentativa, ponderar, nesta última, a primazia do interdiscurso e estudar séries discursivas argumentativas em sua diacronia, superando o curto período do acontecimento e incorporando o médio ou longo prazo. A memória retórico-argumentativa é inerente a determinados posicionamentos ideológicos, nos casos discutidos aqui, trata-se das direitas que na América do Sul apoiaram os golpes militares (FAUSTO; DEVOTO, 2004; DEUSTCH, 2005) ) $^{30}$.

Apesar de Perelman e Pêcheux - como demostrei - assumirem posições epistemológicas muito distintas, no âmbito geral do estudo das memórias discursivas e, especificamente, no da sua dimensão argumentativa, os tipos de argumentos codificados pela Nova Retórica apresentam-se como ferramentas úteis para indagar os modos pelos quais a historicidade penetra a persuasão.

\section{Referências}

ADAM, Jean-Michel; HEIDMANN, Ute. Des genres à la généricité. L'exemple des contes (Perrault et les Grimm). Langages, Paris, n. 153, p. 62-72, 2004.

AGAMBEN, Giorgio. Homo sacer. El poder soberano y la nula vida. Valencia: Pre-textos, 1998.

ALTHUSSER, Louis. Ideología y aparatos ideológicos de Estado. In: La filosofía como arma de la revolución. México: Ediciones del pasado y del presente, 1988.

ALVES, Maria Helena Moreira. Estado e oposição no Brasil (1964-1984). Rio de Janeiro: Vozes, 1989.

30 Em outros estudos (VITALE, 2009; 2013), detive-me nas nuances que permitem distinguir, tanto na Argentina como no Brasil, duas memórias retórico-argumentativas golpistas, vinculadas a distintos setores da direita, um mais extremo e outro mais moderado. 


\section{Linha D'Água (Online), São Paulo, v. 29, n. 2, p. 156-172, dez. 2016}

AMOSSY, Ruth. Nouvelle Rhétorique et linguistique du discours. In: KOREN, R.; AMOSSY, Ruth (Org.). Après Perelman. Quelles politiques pour les nouvelles rhétoriques. L'argumentation dans les sciences du langage. Paris: L'Harmattan, 2002. p. 153-171.

Les enjeux du "déraisonnable": rhétorique de la persuasion et rhétorique du dissensus. In: FRYDMAN, Benoît; MEYER, Michel (Dir.). Chaïm Perelman (1912-2012). De la nouvelle rhétorique à la logique juridique. Paris: PUF, 2012.

ANGENOT, Marc. Le rationnel et le raisonnable. Sur un distinguo de Chaïm Perelman. Montréal: Université McGill, 2012.

ARNOUX, Elvira. El discurso latinoamericanista de Hugo Chávez. Buenos Aires: Biblos, 2008.

AUTHIER-REVUZ, Jacqueline. Ces mots qui ne vont pas de soi. Boucles réflexives et non-coincidences du dire. Paris: Larousse, 1995.

. Palavras incertas. As não coincidências do dizer. Campinas: ED. UNICAMP, 1998.

BAJTÍN, Mikhail. El problema de los géneros discursivos. In: Estética de la creación verbal. México: Siglo XXI, 1982.

CHARAUDEAU, Patrick; MAINGUENEAU, Dominique (Dir.). Diccionario de análisis del discurso. Buenos Aires; Madrid: Amorrortu, 2005.

. La problemática de los géneros. De la situación a la construcción textual. Signos, Valparaiso, v. 37, n. 56, p. 23-39, 2004.

COURTINE, Jean-Jacques. Analyse du discours politique (le discours communiste adressé aux chrétiens). Langages, Paris: n.62, juin 1981.

DANBLON, Emmanuelle. La Nouvelle Rhétorique de Perelman et la question de l'auditoire universel. In: MEYER, Michel (Coord.). Perelman le renouveau de la rhétorique. Paris: Presses Universitaires de France, 2004. p. 21-38.

La fonction persuasive. Anthropologie du discours rhétorique. Origines et actualité. $\mathrm{Pa}-$ ris: Armand Colin, 2005. 
Linha D'Água (Online), São Paulo, v. 29, n. 2, p. 156-172, dez. 2016

DEUTSCH, Sandra McGee. Las derechas. La extrema derecha en la Argentina, el Brasil y Chile 1890-1939. Buenos Aires: Universidad Nacional de Quilmes, 2005.

EAGLETON, Terry. Ideología. Una introducción. Barcelona: Paidós, 1997.

FAUSTO, Boris; DEVOTO, Fernando. Brasil e Argentina. Um ensaio de história comparada (1950-2002). São Paulo: Editora 34, 2004.

FOUCAULT, Michel. La arqueología del saber.12.ed. México: Siglo XXI Editores, 1987.

FUCHS, Cateherine. Paraphrase et énonciation. Paris: Ophrys, 1994.

HERMAN, Thierry; JUFER, Nicole. L'éditorial, “vitrine idéologique du journal”?. Semen, Besançon, n. 13, p. 135-162, 2001.

INDURSKY, Freda. Lula lá: estrutura e acontecimento. Organon, Porto Alegre, n. 35, p. 101$121,2003$.

A memória na cena do discurso. In: INDURSKY, Freda; Mittmann, Solange; FERREIRA, Maria Cristina Leandro (Org.). Memória e história na/da Análise do Discurso. Campinas: Mercado das Letras. 2011.

LAKOFF, George; JOHNSON, Mark. Metáforas de la vida cotidiana. Madrid: Cátedra, 1995.

MALDIDIER, Denise. L'inquiétude du discours. Paris: Éditions des Cendres, 1990.

GARCIA NEGRONI, María Marta. La negación metalingüística: argumentación, gradualidad y reinterpretación. Signo y Seña, Buenos Aires, n. 9, p. 227-252, 1998.

ORLANDI, Eni Puccinelli. Discurso Fundador: a formação do país e a construção da identidade nacional, Campinas: Pontes, 1993.

PÊCHEUX, Michel; FUCHS, Catherine. Actualizaciones y perspectivas en análisis automático del discurso. In: . Hacia el análisis automático del discurso. Madrid: Gredos, 1978.

Les vérités de la Palice. Paris: Hachette, 1975.

O discurso: estrutura ou acontecimento? Campinas: Pontes, 1990.

VITALE, M. A. Memória retórico-argumentativa: encontro entre Perelman e Pêcheux 
Linha D'Água (Online), São Paulo, v. 29, n. 2, p. 156-172, dez. 2016

PERELMAN, Chaïm; OLBRECHTS-TYTECA, Lucie. Tratado de la argumentación. La nueva retórica. Madrid: Gredos, 1989 [1958].

PLANTIN, Christian. Les bonnes raisons des émotions. Principes et méthode pour l'étude du discours émotionné. Berne: Peter Lang, 2011.

VITALE, María Alejandra. Prensa escrita y autoritarismo. Las memorias retórico-argumentales de los discursos golpistas en la Argentina (1930-1976). Buenos Aires, 2006. Tesis (Doctorado) - Facultad de Filosofía y Letras, Universidad de Buenos Aires.

Prensa escrita y autoritarismo. El tópico de la caída hacia el abismo (1930-1976). Páginas de Guarda. Revista de edición, lenguaje y cultura escrita, Buenos Aires, n. 4, p. 47-62, 2007.

La dimensión argumentativa de las memorias discursivas. El caso de los discursos golpistas de la prensa escrita argentina (1930-1976). Forma y Función, Bogotá, n. 1, v. 22, p. 125$144,2009$.

Sentidos de "revolução" e "revolución" na imprensa escrita golpista do Brasil (1964) e da Argentina (1966)”. Bakhtiniana: Revista de Estudos Discurso, São Paulo, n. 8, v. 1, p. 254-274, jan./jun. 2013.

ZOPPI-FONTANA, Mónica. Acontecimento, Arquivo, Memória: às margens da lei. Revista Leitura, Maceió, n. 29, 2004.

Recebido em 30/08/2016.

Aprovado em 07/09/2016. 